\title{
Contribution of rare disease patient organisations to medical education
}

\author{
Rainald von Gizycki \\ From 5th European Conference on Rare Diseases (ECRD 2010) \\ Krakow, Poland. 13-15 May 2010
}

Faced with about 7000 rare diseases, the limited knowledge of physicians is obvious, and deficits in diagnosis and therapy in consequence as well. Rare disease patients however, being usually confronted with only one disease or syndrome during their life time learn to cope with the symptoms, course and specificities of their disease and acquire expertise in diagnostics and treatments, as well as a feeling for a limited competence even of specialists.

As disease-specific patient organisations provide a platform for the exchange of these experiences and for the provision of specialised information and/or services, the question arises: How is the knowledge of patients and the infrastructure of patient organisations utilised not only for the benefit of patients but also for the continuous education of doctors?

A Charité research project in cooperation with ACHSE (German Rare Disease Umbrella Organization), funded by the German Ministry of Health, among other aspects investigates the "Contribution of patient organisations to medical education", by

- implementing a survey of rare disease patient organisations (members of ACHSE),

- providing the documentation, analysis and support of activities of rare disease patient organisations for the training and continuous education of doctors.

As the project is still ongoing at the time of the ECRD, only a few interim results and preliminary recommendations can be presented So far:

\section{Method of data collection}

- E-mail questionnaire survey of 90 member organisations of ACHSE with short introductory paper attached;

Correspondence: rainald.vongizycki@charite.de

Retina Europe, Charite-University Medicine Berlin/Retina Europe
- Good response rate of 58\%, i.e. 52 member organisations responded by end March 2010

Preliminary overall results:

- Most RD patient organisations are actively and successfully involved in numerous activities for and by doctors, researchers and clinicians specialised in the field of their respective diseases;

- Priority is placed on the organisations of annual or biannual conferences, research colloquia and patient days followed by patient-oriented presentations, articles and publications in specialised professional meetings, journals, books etc.

- Training of medical students by patient organisations is far less important than education of doctors although some innovative activities exist.

\section{Major preliminary recommendation:}

The regular observation, collection of data and support of educational activities by RD patient organisations for doctors and medical professionals is recommended, given their specific learning impact and benefit of interaction not only for professionals but also for patients, patient representatives, researchers and the wider public.

Contribution of Rare Disease Patient Organisations to Medical Education in Germany

Published: 19 October 2010

doi:10.1186/1750-1172-5-S1-O25

Cite this article as: von Gizycki: Contribution of rare disease patient organisations to medical education. Orphanet Journal of Rare Diseases 2010 5(Suppl 1):025 